\title{
COW URINE DISTILLATE AS A BIOENHANCER FOR ANTIMICROBIAL \& ANTIPROLIFERATIVE ACTIVITY AND REDISTILLED COW URINE DISTILLATE AS AN ANTICLASTOGEN AGENT
}

\section{SUCHARITHA KANNAPPAN MOHANVEL ${ }^{1 *}$, SATISH KUMAR RAJASEKHARAN ${ }^{2}$, TRISHNA KANDHARI ${ }^{1}$, BALAJI PRASANNA KUMAR GOPAL DOSS ${ }^{1}$, YUVARANI THAMBIDURAI ${ }^{1}$}

${ }^{1}$ Department of Biotechnology, D.G. Vaishnav College, Arumbakkam, Chennai, Tamil Nadu, India. ${ }^{2}$ Center for Research and Development, PRIST University, Thanjavur, Tamil Nadu, India. Email: charusunder@gmail.com

Received: 03 April 2017, Revised and Accepted: 30 June 2017

ABSTRACT

Objective: The objective of this study was to prove that cow urine distillate (CUD) is a bioenhancer for antimicrobial activity and antiproliferative activity, redistilled CUD (RCUD) as an anticlastogen agent.

Methods: The antimicrobial activity of rifampicin with CUD at different concentrations was determined against pathogenic Escherichia coli by well puncture method. The Penicillin and ciprofloxacin in combination with CUD at different/increasing concentrations against pathogenic E. coli culture were also determined by disc diffusion method. Sulforaphane (ACA) as an anticancer agent was extracted from cruciferous vegetables and purified by high-performance liquid chromatography. The Breast cancer cell lines (MCF-7) were treated with anticancer agents along with CUD in increasing concentrations. The anticlastogenic activity of RCUD in human peripheral lymphocytes was tested with clastogens such as manganese dioxide and hexavalent chromium.

Results: CUD showed to enhance the antimicrobial activity of rifampicin with $20 \mu$ l concentration by well puncture method; penicillin with increasing concentration of up to $80 \mu \mathrm{l}$ and ciprofloxacin up to $80 \mu \mathrm{l}$, respectively, by disc diffusion method. The rate of degeneration of breast cancer cell lines (MCF-7) was increased with increasing concentration of CUD. Clastogen $\left(\mathrm{MnO}_{2}\right.$ ) of $10 \mu \mathrm{l}$ with $200 \mu \mathrm{l}$ of RCUD showed effective anticlastogenic activity in agarose gel electrophoresis as the activity of clastogen decreased with increasing concentration of RCUD.

Conclusion: CUD acts as a bioenhancer to increase antimicrobial and antiproliferative activity. RCUD showed a high level of anticlastogenic activity toward clastogen. Thus, cow urine is found to have special properties that can be used in combination with different therapeutic agents to cure several diseases such as tuberculosis, leprosy, and cancer. Further in vivo and clinical studies are required to confirm its therapeutic efficacy.

Keywords: Cow urine distillate, Redistilled cow urine distillate, Bioenhancer, Antimicrobial activity, Antiproliferative activity, Anticlastogen activity.

(C) 2017 The Authors. Published by Innovare Academic Sciences Pvt Ltd. This is an open access article under the CC BY license (http://creativecommons. org/licenses/by/4. 0/) DOI: http://dx.doi.org/10.22159/ajpcr.2017.v10i10.18879

\section{INTRODUCTION}

According to the Vedas, the cow was considered as a most valuable animal and called as the mother of all [1]. Cow's urine was known as "GOMUTRA" has many advantages in curing several diseases [2]. It has a unique place in Ayurveda and was described as an effective medicinal substance or secretion of animal origin with innumerable therapeutic properties [3]. It is an important ingredient of panchagavya, a term used to describe five major substances such as urine, milk, ghee, curd, and dung obtained from cow $[3,4]$. All the five products possess medicinal properties and are used singly or in combination with some other herbs against many diseases $[5,6]$. This kind of alternative treatment, termed as "cowpat," has been reported [7] to be beneficial even for threatening diseases such as cancer, AIDS and diabetes, and tuberculosis [8]. Different preparations were available nowadays such as urine distillate, photoactivated urine [9], fresh urine, and sterile urine in affordable prices [10]. The urine distillate was not found to be active among all the cow urine preparations; the results were reported contradictory to others [11].

Various analyses done on cow urine, revealed the presence of substances such as nitrogen, sulfur, phosphate, sodium, manganese, iron, silicon, chlorine, magnesium, malic, citric, tartaric, succinic, carbolic acids, calcium salts, Vitamins A, B, C, D, E, lactose, enzymes, creatinine, hormones, and gold acids. Therefore, these are needed in smaller amounts by the human body to cure various diseases. The presence of certain volatile and nonvolatile components was also present in cow's urine [12].
The cow urine distillate (CUD) is used as a bioavailability facilitator for anticancer therapy directly or in combination with anticancer molecules [2]. The bioactive fraction enhances the activity of antibacterial agents, anticancer agents, and antituberculosis agents from 2 to 80 folds and helps the antibiotics and other molecules to act better on the target by transferring the compound across the membrane to the target site.

Sulforaphane and diindolylmethane (compounds from brassica vegetables) have been shown to synergize together in inhibition of cancer growth. The former compound has cancer chemopreventive activity and is also classified as an isothiocyanate [3]. Sulforaphane is a glycol breakdown product of the glucosinolate glucoraphanin (sulforaphane glucosinolate). Young broccoli sprouts and cauliflower, sprouts are especially rich in glucoraphanin [6].

A clastogen is a mutagenic agent form mutagenesis, and it is human carcinogens as well [11], an anticlastogen is an agent that inhibits or suppresses the activity of clastogen [13]. Various research studies have already reported regarding the redistilled CUD (RCUD) as an anticlastogenic agent [14].

The present work was aimed at proving CUD as a bioenhancer for antimicrobial activity [15] and anticancer activity and RCUD as an anticlastogenic agent. To prove, the antimicrobial activity of CUD in various concentrations was tested against different antibiotics. Similarly, the anticancer activity of CUD with different anticancer agents 
against cancer cell lines was checked. The anticlastogenic activity of RCUD in human peripheral lymphocytes was tested with clastogens namely manganese dioxide and hexavalent chromium.

\section{METHODS}

\section{Collection of sample (CUD)}

CUD was collected from Asaram Gow-Shala, bypass tank road, Niwai, Rajasthan

\section{CUD - bioenhancer for antimicrobial activity}

About $50 \mathrm{ml}$ of Luria-Bertani broth was autoclaved at $121^{\circ} \mathrm{C}$ for 15 minutes and followed by inoculating with Escherichia coli (Diagnostic Centre at Mambalam, Chennai), it was incubated at $37^{\circ} \mathrm{C}$ in orbital shaker overnight.

\section{Well puncture method}

Mueller-Hinton agar (MHA) was autoclaved at $121^{\circ} \mathrm{C}$ for 15 minutes. Rifampicin was prepared using sterile distilled water at a concentration of $1 \mathrm{mg} / \mathrm{ml}$ wells were created in the medium using gel puncture. E. coli broth culture was uniformly spread over the medium using a sterile swab. Rifampicin added in the wells as standard concentration of $10 \mu \mathrm{l}$ would act as a control. CUD was added in different concentrations of $10 \mu \mathrm{l}, 20 \mu \mathrm{l}$. The plates were incubated at $37^{\circ} \mathrm{C}$ for $48 \mathrm{hrs}$ [2].

\section{Disc diffusion method}

MHA was prepared and autoclaved at $121^{\circ} \mathrm{C}$ for 15 minutes. Using a sterile swab $E$. coli broth culture was uniformly spread over the media. Penicillin and ciprofloxacin discs were placed on the media. CUD was added in the concentration of $20 \mu \mathrm{l}, 40 \mu \mathrm{l}, 60 \mu \mathrm{l}$, and $80 \mu \mathrm{l}$. The plates were incubated at $37^{\circ} \mathrm{C}$ for $48 \mathrm{hrs}$ [2].

\section{Extraction of anticancer agent from broccoli sprouts and cabbage seeds}

Broccoli sprouts and cabbage seeds were rinsed with distilled water. It was then grounded using mortar and pestle. Ground sprouts and seeds were defeated thrice with hexane and allowed to dry overnight at room temperature. Milli-Q water was added in 3:1 ratio $(\mathrm{w} / \mathrm{w})$ to defatted meal, father was allowed to utilize for $8 \mathrm{hrs}$ at room temperature. Sodium chloride:wet meal:sodium sulfate was added in the ratio 1:1:0.75 $(\mathrm{w} / \mathrm{w} / \mathrm{w})$ and mixed thoroughly followed by extracting thrice with equal volumes of methylene chloride. It was centrifuged at $4,000 \mathrm{rpm}$ for 10 minutes. Upper aqueous phase was collected in a separate centrifuge tube. The liquid was filtered using a Whatman filter paper. The filtrate was stored in the refrigerator [16-18].

\section{High-performance liquid chromatography (HPLC)}

Preparative HPLC separation was performed by injecting $0.5 \mathrm{ml}$ of filtered aqueous extract onto a Waters Prep Nova-Pak $(19 \times 300 \mathrm{~mm}$, $60 \AA, 6 \mu \mathrm{m}$ ) HR C-18 reversed-phase HPLC column (Waters, Milford, MA). Elution was performed using Waters model 501 pumps to deliver a constant flow rate. The solvent system consisted of $50 \%$ acetonitrile in water. Sulforaphane was detected by absorbance at $254 \mathrm{NM}$ using a ultraviolet (UV) detector (19).

\section{Maintenance of breast cancer cell lines}

Breast cancer cell lines (MCF-7) strains were ordered from National Centre for Cell Sciences (NCCS) from Pune. The confluent cells from NCCS were subcultured and maintained aseptically followed by examining under phase contrast microscope. They used up medium was discarded, and monolayer was rinsed with PBS. $1 \mathrm{ml}$ of $0.25 \%$ trypsin ethylenediaminetetraacetic acid was added to dislodge the cells, and it was monitored to prevent overexposure of cells to enzyme trypsin. Once the cells were detached, the cell count and viability were checked. $5 \mathrm{ml}$ of Dulbecco's Modified Eagle's medium (DMEM) medium was added along with $10 \%$ fetal bovine serum (FBS), and the flask was incubated at $37^{\circ} \mathrm{C}$ in $5 \% \mathrm{CO}_{2}$ incubator
Anticancer activity of broccoli extract and cabbage seed extract in the presence of CUD

About $200 \mu \mathrm{l}$ of breast cancer cells with the medium was taken on a 24 well titer plate. $500 \mu \mathrm{l}$ of media along with $10 \%$ FBS was added to each well. The titer well plate was incubated overnight at $37^{\circ} \mathrm{C}$ in $5 \%$ $\mathrm{CO}_{2}$ incubator for $24 \mathrm{hrs}$. The medium was replaced with fresh $500 \mu \mathrm{l}$ of DMEM along with 10\% FBS. The test component (anticancer agent from broccoli and cabbage seed) was added at a standard concentration of $100 \mu \mathrm{l}$ in each well followed by addition of CUD with increasing concentrations $(100 \mu \mathrm{l}, 200 \mu \mathrm{l}$, and $300 \mu \mathrm{l})$. Controls were set with $100 \mu \mathrm{l}, 200 \mu \mathrm{l}$ of anticancer agent alone and the titer well plate was incubated overnight at $37^{\circ} \mathrm{C}$ in $5 \% \mathrm{CO}_{2}$ incubator.

\section{RCUD - anticlastogenic agent \\ Redistillation of CUD}

CUD was redistilled. The single distilled cow urine was acidified by lowering the $\mathrm{pH}$ below 2.0 with the addition of $85 \%$ orthophosphoric acid. Cow urine was again distilled at $100^{\circ} \mathrm{C}$ using a temperature controlled distillation apparatus to remove ammonia.

\section{Preparation of clastogen agents}

The clastogen agents, namely, manganese dioxide $\left(\mathrm{MnO}_{2}\right)$ in $1.2 \mathrm{mmol} / \mathrm{liter}$ and chromium trioxide $(\mathrm{Cr}+6) 5 \mu \mathrm{mol} / \mathrm{l}$ were prepared.

\section{Clastogenic assay}

About $2 \mathrm{ml}$ of human venous blood was collected in a tube containing heparin sodium salt. $3.5 \mathrm{ml}$ of DMEM was taken in a T-flask using a syringe filter. $20 \%$ of FBS was added to the flask using a pipette. $500 \mu \mathrm{l}$ phytohemagglutinin (mitogen) was added to each flask and $0.5 \mathrm{ml}$ of heparinized blood was added to each flask. The flasks were incubated overnight at $37^{\circ} \mathrm{C}$ in $5 \% \mathrm{CO}_{2}$ incubator, after 24 hrs the flasks were viewed under phase contrast microscope for lymphocyte cell culture followed by discarding the medium. The cells were washed with PBS twice, fresh medium were added along with 10\% FBS to each flask. The human peripheral lymphocytes were pretreated with RCUD at different concentrations $(200 \mu \mathrm{l}, 400 \mu \mathrm{l})$ and were incubated at $37^{\circ} \mathrm{C}$ in $5 \% \mathrm{CO}_{2}$ incubated for $1 \mathrm{hr}$. After an hour the lymphocyte cells were then treated with clastogens at different concentrations as $10 \mu \mathrm{l}$ in $200 \mu \mathrm{l}$ RCUD and $40 \mu \mathrm{l}$ in $400 \mu \mathrm{l}$ RCUD, respectively, $30 \mu \mathrm{l}$ of clastogen agent were added to the control flask and the flasks were incubated at $37^{\circ} \mathrm{C}$ in $5 \% \mathrm{CO}_{2}$ incubator for $48 \mathrm{hrs}$ [14].

\section{Isolation of DNA from lymphocytes}

About $2 \mathrm{ml}$ of the treated lymphocyte culture was taken along with the medium in a centrifuge tube followed by adding $2 \mathrm{ml}$ of SE buffer and mixed by vortexing. $2 \mathrm{ml}$ of $0.2 \%$ freshly prepared SDS was added and mixed thoroughly, the tubes were incubated at $65^{\circ} \mathrm{C}$ for $1 \mathrm{hr}$ in dry bath. $400 \mu \mathrm{l}$ of $2 \mathrm{M} \mathrm{NaCl}$ was added to the tubes and mixed by inverting the tubes gently. Tubes were centrifuged at 10,000 RPM for 15 minutes at $4^{\circ} \mathrm{C}$ and the supernatant was carefully transferred to centrifuge tubes and the pellet was discarded. Double the volume of ice cold absolute ethanol was added to each tube, the tubes were gently inverted several times until the DNA precipitate was formed. Visible DNA strands were transferred to microfuge tube followed by adding $200 \mu$ l of $70 \%$ ethanol and tubes were centrifuged at 2,000 rpm for 5 minutes. The supernatant was discarded, the pellet was air dried, after drying it was re-suspended with $200 \mu \mathrm{l}$ of TE buffer and stored at $-20^{\circ} \mathrm{C}$. Finally, the isolated DNA from clastogen treated lymphocyte was viewed by running gel electrophoresis [14].

\section{RESULTS}

\section{Antimicrobial activity}

The antimicrobial activity of rifampicin was increased when in combination with CUD in different concentrations $10 \mu \mathrm{L}$ and $20 \mu \mathrm{L}$, respectively. Rifampicin + CUD showed a clear zone of inhibition, whereas rifampicin alone shows a pale zone of inhibition. Therefore, the 
microbial activity of rifampicin increased with increasing concentration along with CUD. $20 \mu \mathrm{L}$ showed larger zone of inhibition compared with rifampicin + CUD $(10 \mu \mathrm{L})$. Hence, it was proved that CUD is bioenhancer for the microbial activity of antibiotic rifampicin

Disc diffusion method with penicillin + CUD showed the zone of inhibition is same as in control and even with $20 \mu \mathrm{l}$ of CUD after $24 \mathrm{hrs}$ of incubation. However, after $48 \mathrm{hrs}$ of incubation the zone of inhibition with $40 \mu \mathrm{l}, 60 \mu \mathrm{l}$, and $80 \mu \mathrm{l}$ CUD concentrations were observed and were found to be effective (Fig. 1).

The zone of inhibition was found to increase with increasing concentration $20 \mu \mathrm{L}, 40 \mu \mathrm{L}, 60 \mu \mathrm{L}$, and $80 \mu \mathrm{L}$ of the CUD + ciprofloxacin disc. Percentage of the zone of inhibition increases with CUD concentration, hence proving that CUD is an enhancer for antimicrobial activity (Fig. 2)

Two distinct layers as upper aqueous phase and lower organic phase, the former contains the anticancer agent. The HPLC peak (sharp peak) for the extracts from broccoli sprouts was seen in Fig. 3 and indicates that the compound has very less impurities, whereas in Fig. 4 shows that the cabbage seed extract has a high level of impurity when compared to the broccoli sprouts.

After 24 hrs of incubation, the degeneration of breast cancer cell lines was seen by a broccoli anticancer agent alone and therefore the increase in degeneration rate with the increase in the concentration of CUD with broccoli sprouts. Degeneration of cancer cells with cabbage seeds was less as the purity of sample was less found by HPLC results. Redistillation of CUD was done to check the anticlastogen activity Fig. 5 shows the normal lymphocyte culture and treated lymphocytes with clastogen and RCUD was seen in Fig. 6.

Isolation of DNA was done from lymphocyte and run at $1 \%$ and $0.8 \%$ agarose gel seen in Figs. 7 and 8. The lane 3, 4 with $10 \mu \mathrm{l} \mathrm{MnO}_{2}+200$ $\mu \mathrm{l}$ of RCUD, showed the high clastogenic activity as the concentration of RCUD was less in lane 5 and 6 with $40 \mu \mathrm{l} \mathrm{MnO}_{2}+400 \mu \mathrm{l}$ of RCUD comparatively, this explains the anti-clastogen activity of RCUD. Fig. 9 shows the activity of RCUD as an anticlastogenic agent.

\section{DISCUSSION}

Cow's urine is a mobile medical dispensary, and it's a panacea of all diseases stated by Pathak and Kumar [19]. Cow's urine is believed to cure many diseases [20] as the CUD, bioenhancer for antimicrobial activity proved by disc diffusion method and well puncture method. In accordance to Wate et al., 2011 distillate cow's urine, an activity enhancer and availability facilitator for bio active molecules such as antibiotic, antifungal, and anticancer drugs [21]. The CUD was added in increasing concentrations of $20 \mu \mathrm{l}, 40 \mu \mathrm{l}, 60 \mu \mathrm{l}$, and $80 \mu \mathrm{l}$ and the results were found to be more effective in disc diffusion method, and therefore it shows an effective enhancing property to antibiotics rifampicin, penicillin, and ciprofloxacin within 48 hrs of incubation. Therefore, similar results were expressed by Khanuja et al., 2002 showed that the activity of antibiotic rifampicin and penicillin used alone and several folds activity increased when used in combination with CUD in addition to that Vijayalakshmi and Saranya stated that Gomutra has both antifungal $[22,23]$ and antibacterial activity.

According to Vermeulan et al., 2006 extraction of anticancer agents from a plant source is the most economical method, the cruciferous vegetables such as broccoli, brussels sprouts, and cabbage, can lower the risk of developing pancreatic, lung, colorectal, and prostate cancers [18,24,25]. According to Kushad et al., 1999, the broccoli seeds were found to be rich in glucosinolates or isothiocyanate [26] compounds as HPLC was performed using HR C-18 reversed-phase column, the solvent system consisted of $10 \%$ acetonitrile in water and therefore his findings revealed the presence of compound sulforaphane at $254 \mathrm{~nm}$ absorbance using a waters 486 tunable absorbance detector (Waters, Milford, MA) [27]. In our present work, the anticancer agent

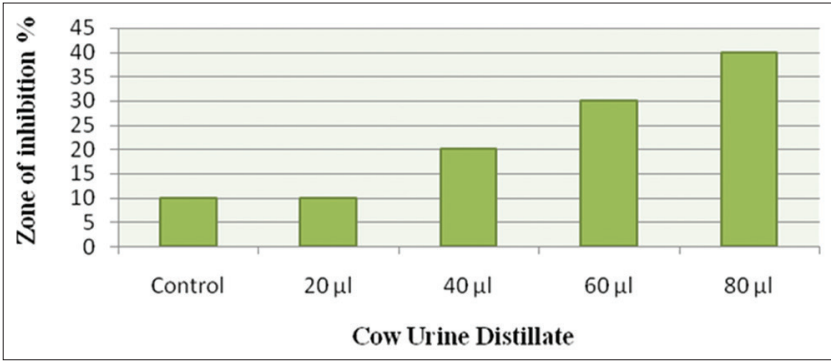

Fig. 1: Antibiotic activity penicillin with cow urine distillate

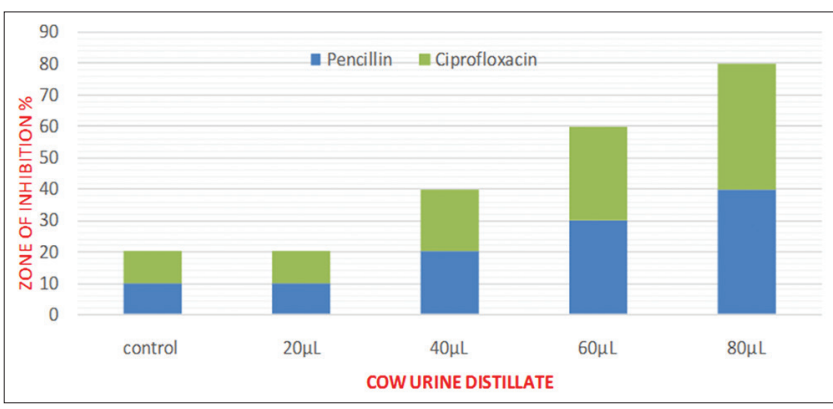

Fig. 2: Antibiotic activity (penicillin and ciprofloxacin) with cow urine distillate

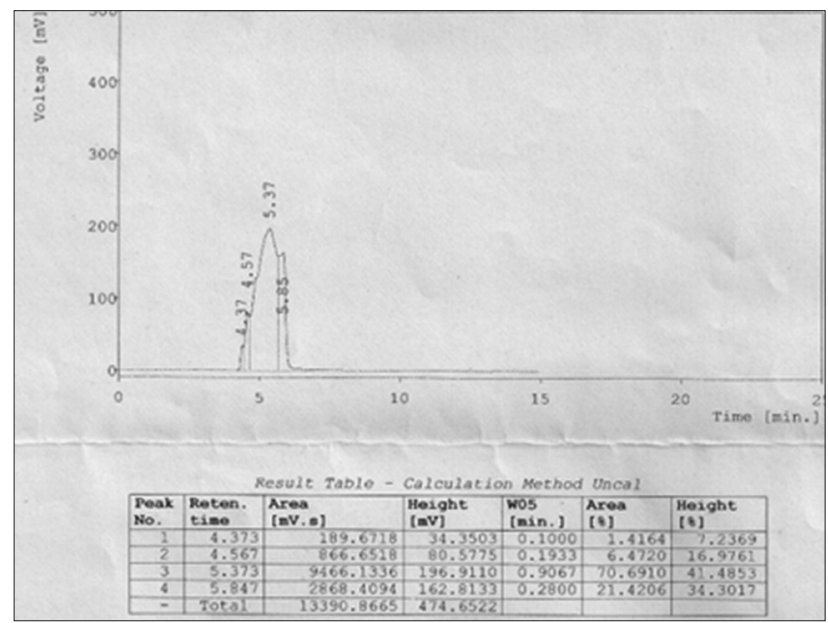

Fig. 3: High-performance liquid chromatography for broccoli sprouts extract

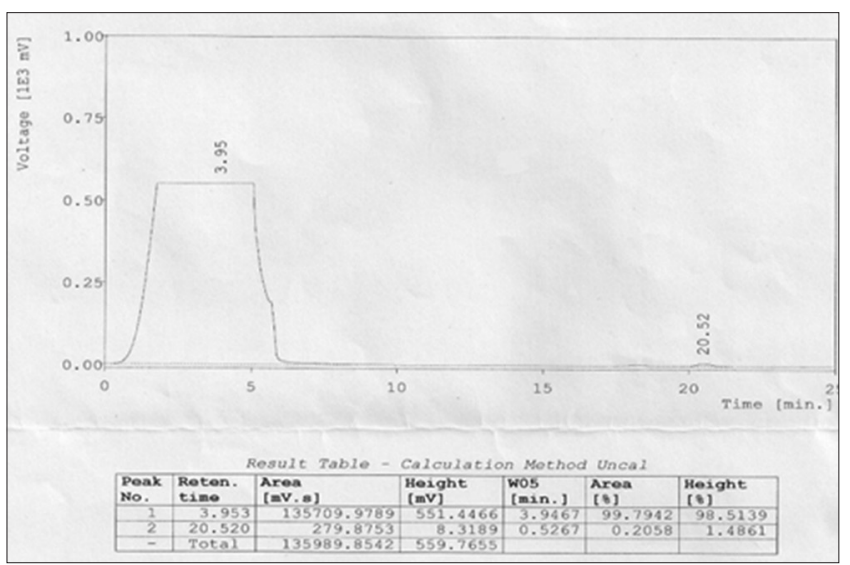

Fig. 4: High-performance liquid chromatography for cabbage seed extract 


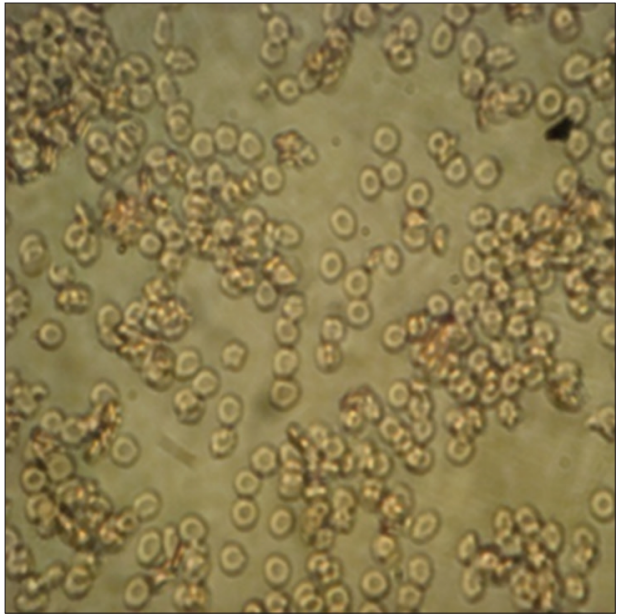

Fig. 5: Normal lymphocyte

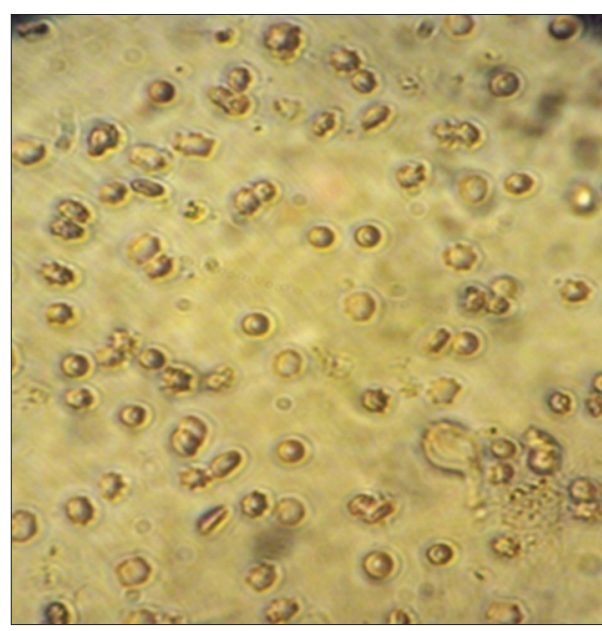

Fig. 6: Treated lymphocyte

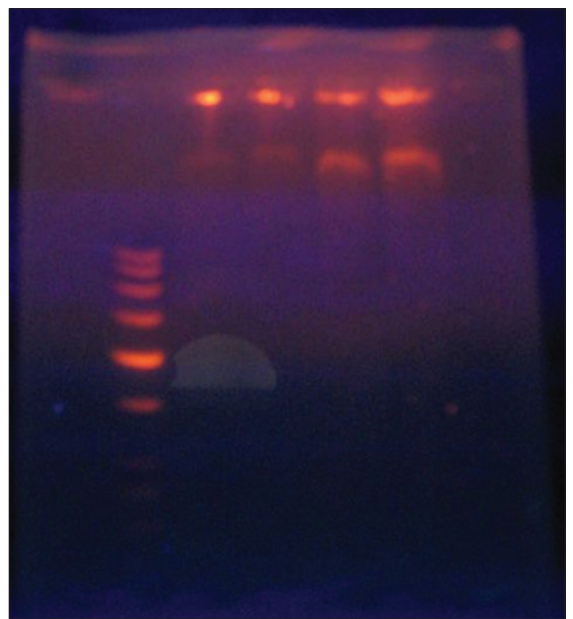

Fig. 7: 1\% agarose

sulforaphane, a glucosinolate was extracted from broccoli sprouts and cabbage seeds, followed by preparative HPLC by injecting $0.5 \mathrm{ml}$ of filtered aqueous extract onto a C-18 column with a solvent system consisting of $50 \%$ acetonitrile in water, their purity was detected by absorbance at $254 \mathrm{~nm}$ using a UV detector. The peaks of HPLC reveal the presence of impurities as the broccoli extract has less impurities when compared to the cabbage seeds.

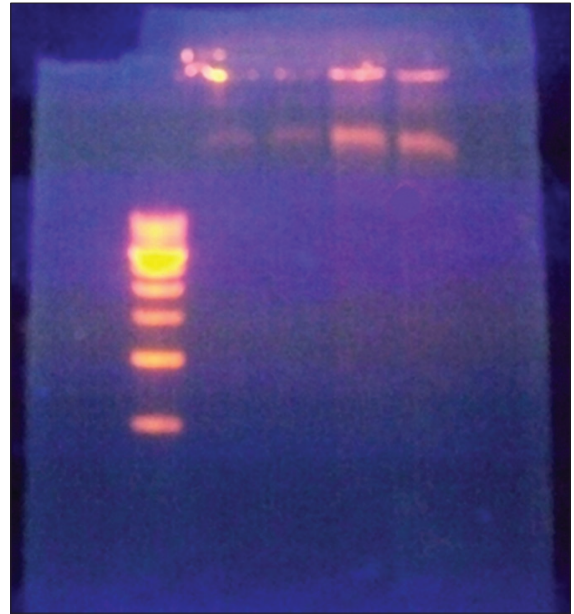

Fig. 8: 0.8\% agarose

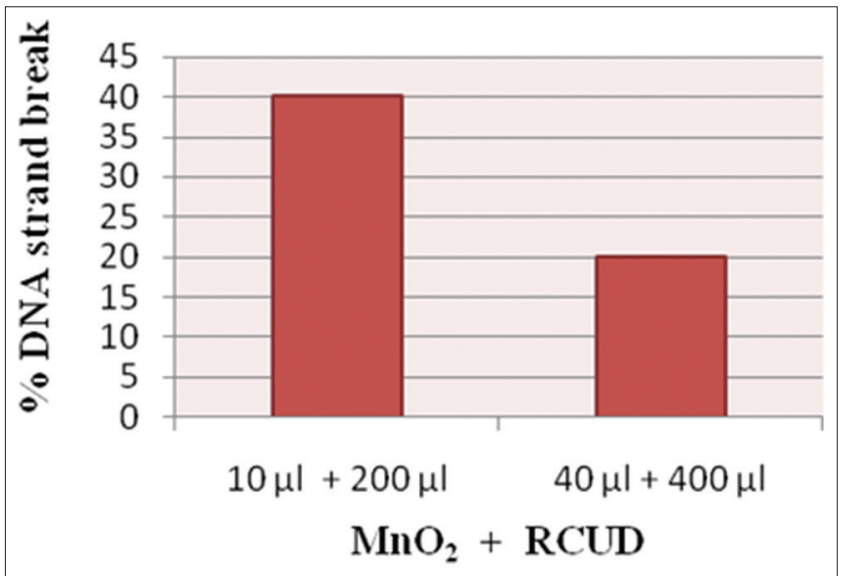

Fig. 9: Anticlastogenic property

Randhawa, 2010 stated that CUD as a bioenhancer for anticancer agents, in the present study anticancer agent was extracted from broccoli sprouts and cabbage seeds [28]. The MCF-7 was treated with sulforaphane as control $(100 \mu \mathrm{l}, 200 \mu \mathrm{l})$ and sulforaphane (ACA) along with CUD in increasing concentrations $(100 \mu \mathrm{l}$ ACA + $100 \mu \mathrm{l}$ CUD, 100 $\mu \mathrm{l} \mathrm{ACA}+200 \mu \mathrm{l}$ CUD, and $100 \mu \mathrm{l} \mathrm{ACA}+300 \mu \mathrm{l}$ CUD) followed by adding the ACA of about $100 \mu \mathrm{l}$. As the concentration of CUD increased with the rate of degeneration of breast cancer cells was also increased gradually, and degeneration was observed maximum in $100 \mu \mathrm{l}$ ACA $+300 \mu \mathrm{l} \mathrm{CUD.}$ Hence, CUD acts as an enhancer of anticancer agent [26]. Dutta et al., 2005 reported that the anticlastogenic and antigenotoxic effect of RCUD in human peripheral lymphocytes, which has been challenged with manganese dioxide $\left(\mathrm{MnO}_{2}\right)$ and hexavalent chromium $(\mathrm{Cr}+6)$. Human peripheral lymphocytes in vitro were treated with manganese dioxide and hexavalent chromium as established genotoxicants and clastogens which could cause induction of DNA strand break, chromosomal aberration and micronucleus [29]. Our present work showed that three different concentrations of RCUD such as $1 \mu \mathrm{L} / \mathrm{ml}, 50 \mu \mathrm{L} / \mathrm{ml}$, and $100 \mu \mathrm{L} / \mathrm{ml}$ were used and the manganese dioxide and hexavalent chromium caused statistically significant damages to DNA, which could be protected by RCUD which in turn confirmed the clastogenic effect by the clastogenic assay.

The anticlastogenic effect of RCUD revealed that the concentration of clastogen to that of RCUD, i.e., $10 \mu \mathrm{L} \mathrm{Mno}{ }_{2} / \mathrm{Cr}^{+6}+200 \mu \mathrm{L}$ of RCUD and $40 \mu \mathrm{L} \mathrm{Mno}_{2} / \mathrm{Cr}^{+6}+400 \mu \mathrm{L}$ of RCUD, as latter causes DNA strand break and the difference in thickness of a DNA band showed the effect of RCUD as anticlastogenic agent and the control was treated with $30 \mu \mathrm{L}$ of $\mathrm{MnO}_{2} / \mathrm{Cr}^{+6}$ whereas the lymphocytes were pretreated $(1 \mathrm{hr}$ before the treatment of clastogens) with RCUD for better results. 


\section{CONCLUSION}

The present work proved that the CUD serves as a bioenhancer for antimicrobial activity by testing against different antibiotics; anticancer activity was being tested in MCF-7 cell lines and RCUD as an anticlastogenic agent toward clastogens. Therefore, cow`s urine has potential to cure several major adverse diseases, as this imparts the vital therapeutic effect of CUD. Further, in vivo study has to be conducted to prove the anticancer activity.

\section{REFERENCES}

1. Shah CP, Patel DM, Dhami PD, Kakadia J, Bhavsar D, Vachhani UD, et al. In vitro screening of antibacterial activity of cow urine against pathogenic human bacterial strains. Int J Curr Pharm Res 2011;3(2):91-2.

2. Khanuja SP, Kumar S, Shasany AK, Darokar MP, Singh M, Sinha P et al. Use of Bioactive Fraction from Cow Urine Distillate ('GoMutra') as a Bio-Enhancer of Anti-Infective, Anti-Cancer Agents and Nutrients". (US Patent No. 6,410,059).

3. Shah E. Herbal Composition in Cow Urine Distillate. US Patent No. 5693327; 1997.

4. Mohanty I, Senapati MR, Jena D, Pallai S. Diversified uses of cow urine. Int J Pharm Pharm Sci 2014;6:20-2.

5. Krishnamurthi K, Dutta D, Devi SS, Chakrabarti T. Protective effect of distillate and redistillate of cow's urine in human polymorphonuclear leucocytes challenged with established genotoxic chemicals. Biomed Environ Sci 2004;17:57-66.

6. Chauhan RS, Singh BP, Singhal LK. Immunomodulation with Kamdhenu ark in mice. J Immunol Immunolpathol 2001;71:89-92.

7. Edwin J, Sheej E, Vaibhav T, Rajesh G, Emmanuel T. Antioxidant and antimicrobial activities of cow urine. Glob J Pharmacol 2008;2(2):20-2.

8. Chawla PC. Resorine a novel CSIR drug curtails TB treatment. CSIR News 2010;60:52-4.

9. Vats S, Kumar R, Negi S. Natural food that meet antibiotics resistance challenge: In vitro synergistic antimicrobial activity of Azadirachta indica, Terminalia chebula, Piper nigrum and photoactivated cow urine. Asian J Pharm Biol Res 2012;2:122-6.

10. Arunkumar S, Muthuselvam M, Rajasekran R. Antimicrobial activities of cow urine distillate against some clinical pathogens. Glob J Pharmacol 2010;4(1):41-4.

11. Shaw SL, Mitloehner FM, Jackson W, Depeters EJ, Fadel JG, Robinson PH et al. Volatile organic compound emissions from dairy cows and their wastes as measured by proton transfer-reaction mass spectrometry. Environ Sci Technol 2007:14:1310-6.

12. Dharma K, Rathore R, Chauhan R, Panchagavya S. (Cow pathy): An overview. Int J Cow Sci 2005;1(2):26-9.

13. Bhalli JA, Shaddock JG, Pearce MG, Dobrovolsky VN. Sensitivity of the pig-an assay for detecting gene mutations in rats exposed acutely to strong clastogens. Mutagenesis 2013;28:447-55.

14. Dutta D, Devi SS, Krishnamurthi K, Chakrabarti T. Anticlastogenic effect of redistilled cow's urine distillate in human peripheral lymphocytes challenged with manganese dioxide and hexavalent chromium. Biomed Environ Sci 2006;19:487-94.

15. Sathasivam A, Muthuselvam M, Rjendran R. Antimicrobial activities of cow urine distillate against some clinical pathogens. Glob J Pharmacol 2010;4:41-4.

16. Zhang Y, Talalay P, Cho CG, Posner G. A major inducer of anticarcinogenic protective enzymes from Broccoli: Isolation and elucidation of structure. Proc Natl Acad Sci USA 1992;89:2399-403.

17. Kushad MM, Brown AF, Kurilich AC, Juvik JA, Klein BP, Wallig MA, et al. Variation of glucosinolates in vegetable crops of Brassica oleracea. J Agric Food Chem 1999;47(4):1541-8.

18. Kintzios SE. Terrestrial plant-derived anticancer agents and plant species used in anticancer research. Crit Rev Plant Sci 2006;25(2):79-113.

19. Pathak ML, Kumar A. Gomutra-descriptive study. Sachitra Ayurveda 2003;7:81-4

20. Lakshmi P. Potential source of fresh and photoactivated gomutra for study of antioxidant and antipathogenic activities against various pathogens. Int J Pharm Pharm Sci 2014;8:459-62.

21. Wate SP, Dhanjode DP, Duragkar NJ, Tajne MR. Antioxidant potential of cow urine and its fractions: A comparative study. Int J Univ Pharm Life Sci 2011;1(1):146-54.

22. Deshmukh SS, Rajgure SS, Ingole SP. Antifungal activity of cow urine. IOSR J Pharm 2012;2(5):27-30.

23. Zhang Y, Li J, Tang L. Cancer-preventive isothiocyanates: Dichotomous modulators of oxidative stress. Free Radic Biol Med 2005;38(1):70-7.

24. Hao L, Chun-Fang L, Qi-Peng Y, Vriesekoop F. Separation and purification of sulforaphane from Broccoli seeds by solid phase extraction and preparative high-performance liquid chromatography. J Agric Food Chem 2007;55(20):8047-53.

25. Matusheski NV, Wallig MA, Juvik JA, Klein BP, Kushad MM, Jeffery EH. Preparative HPLC method for the purification of sulforaphane and sulforaphane nitrile from Brassica oleracea. J Agric Food Chem 2001:49:1867-72.

26. Ipsita M, Manas RS, Deepika J, Santwana P. Diversified uses of cow urine. Int J Pharm Pharm Sci 2014;6(3):20-2.

27. Vermeulen M, van den Berg R, Freidig AP, van Bladeren PJ, Vaes WH. Association between consumption of cruciferous vegetables and condiments and excretion in urine of isothiocyanate mercapturic acids. J Agric Food Chem 2006;54:5350-8

28. Randhawa GK. Cow urine distillate as bioenhancer. J Ayurveda Integr Med 2010;1:240-1

29. Vijayalakshmi R, Saranya VT. Effect of "go-mutra" on plant growth and its antifungal and antibacterial activity. J Herbal Sci Technol 2010;6:6-11 